\title{
Remote Individual Training
}

\author{
Irina N. Fardeeva, Indira A. Shakirova, Elena N. Maltseva, Valentina I. Kuzmenko, Sergey Kh. \\ Peteraitis
}

\begin{abstract}
Modern information technology has firmly entered our lives, which has affected the learning process in higher education. Individual distance learning has been reflected in the development of new teaching methods for people with disabilities, however, more recently, more attention has been paid to the issue of introducing distance learning and for people who, due to circumstances (remote access), cannot be in an educational institution.
\end{abstract}

Individual distance learning is currently a promising form of education for high-quality higher education, since one of the tasks of modern education is unlimited access to high-quality educational resources regardless of gender, race, social status, place of residence, etc. This type of training can be described as a process of providing access to classical modern education, when the source of information and the students themselves are separated in time and space.

The theoretical and methodological basis of this article is based on work in the field of computer science and pedagogy, which explores various processes, methods and means of using computer technology for distance learning in universities.

This article is devoted to the issue of consideration of technologies used for independent activities in the framework of distance individual learning. The authors conducted a study of the results of distance individual learning. It was found that interactive lectures, video conferencing, audiovisual tools, interactive seminars, glossaries, interactive tests are considered the most effective technologies for independent work of students. The results made it possible to emphasize the effect of the development of distance learning technologies.

Keywords: distance individual learning; lifelong education, learning process, electronic resource, information systems.

\section{INTRODUCTION}

The concept of distance learning implies greater access and flexibility in educational opportunities for students, as well as reaching individuals and groups of students regardless of time or geographical location. Distance learning can be considered as an area of education where modern information technologies are used to achieve learning goals. It should be noted that distance learning includes distance learning, home schooling, self-study, continuing education; student-centered learning where personal communication between the teacher and student is not required.

Despite the great interest of scientists in the topic and the large number of existing works, it should be noted the lack of special literature necessary for distance learning in universities, since this type of training in Russia is not popular and is not sufficiently equipped with modern computer

Revised Manuscript Received on November 08, 2019.

* Correspondence Author

Irina N. Fardeeva, Kazan Federal University

Indira A. Shakirova, Kazan Federal University

Elena N. Maltseva, Kazan Federal University

Valentina I. Kuzmenko, Kazan Federal University

Sergey Kh. Peteraitis, Togliatti State University, Russia

didactic materials. There is a clear shortage of educational materials in the form of electronic books, which can be used as additional resources for independent work of students [1]. A.A. Andreev, O.V. Akulova, M.Yu. Bukharkina, E.S. Polat is considered remote individual learning from the point of view of a sociocultural phenomenon, the possibilities of which can be developed both at school and at a university. A.A. Andreev, Vlasova, V.V. Laptev, T.N. Noskova, E.S. Polat noted that this type of training can be introduced into the educational process with the help of new information technologies of a single discipline, as well as the entire training system as a whole, developing inter-university communications. A.Z. Ibatova, A.G. Ilyin consider distance learning as an opportunity to use massive open online courses [2].

The process of studying at a university as a system is two-way and consists of two parts - teaching (teacher's activity) and teaching (student's activity). Distance individual learning is more oriented towards independent activity of students, where the main emphasis is on the creative potential and intellectual development of students. Since the term "distance learning" means distance learning, traditional teaching aids such as lectures, seminars, colloquiums still exist, although communication between the teacher and the student is minimized.

\section{METHODS}

This article uses content analysis methods to study the relevant literature on this topic. The method of system-structural analysis of the main modern terms and concepts allows us to more accurately understand their applicability in the study. The method of systematizing the results allows us to summarize the results of the studies and draw us the appropriate conclusions. The synergistic approach in this study allowed us to consider the organization of individual learning through the prism of the systematic and self-organizing activities of the individual that underlie the social and professional sphere.

\section{RESULTS AND DISCUSSION}

The results of the study show that it is necessary to introduce mechanisms of an individual approach to training in distance learning courses. The article provides the main theoretical recommendations on the use of distance learning methods that allow the teacher to influence the consciousness of each student through technical capabilities, applying their pedagogical skills. The practical significance of this work is that the results can be used to eliminate existing problems in distance education. 
Distance Learning (DL) is a modern correspondence course that includes communicating with the teacher via the Internet. In the learning process, the student learns the materials that are sent by the teacher. The student knows his teacher and methodologist, he can ask questions and receive answers. Distance learning is offered along with full-time, distance learning and evening distance learning [3].

Distance individual learning has several features:

1. Flexibility. The system of remote individual learning allows students to learn on the basis of remote access at any time convenient for them, while they can use an acceptable learning rate. This is a great advantage for people who cannot change their lifestyle, and especially for people with disabilities. For example, the educational virtual platform "Moodle" meets the requirements of the modern educational process due to its flexible capabilities.

2. Communicative. Distance individual learning is a form of learning, where the interaction between the teacher and the student helps to develop the communicative competence of students outside the learning process.

3. Multimedia educational materials allow the creation of more favorable conditions for improving the general competencies of students.

4. Forum and chat enable students to develop certain skills and experience necessary for the learning process.

5. Specific quality control of training. In individual distance learning, organized forms of control in the form of tests are used. The teacher, analyzing the performance of students in assessing the quality of acquired knowledge, can change the material and improve the content of the course if the student has difficulty learning it.

6. Efficiency: distance learning systems are generally considered more cost-effective than traditional full-time education $[4,5]$.

Distance individual learning performs a number of functions:

- improving the educational process, while increasing the level of training of students;

- new learning tools are being introduced using software tools;

- the student is provided with all the necessary materials in electronic form;

- constant monitoring of student performance is carried out, while the teacher has the opportunity to monitor the learned material at the rate;

- there is a direct interactive interaction of the teacher with each student;

- If possible, the teacher can supplement or correct the material.

The distance learning system has recently achieved unprecedented growth and is expanding worldwide. According to the results of the Hannover study, there is a rapid increase in demand for distance learning throughout the world - from 100,000 to 500,000 students annually undergo individual distance learning at major universities around the world. In particular, Africa and India are identified as the two main centers where distance learning is in high demand. It should be noted that most educational institutions in these countries are switching to the use of the Internet as a learning tool not only remotely, but for full-time students [6-14].

Using online learning, especially at a distance, offers flexibility and facilitates the interaction between student and teacher. E-learning includes the development and delivery of effective learning experiences through appropriate information and communication technologies (ICT), where educational content can be delivered using a wide range of electronic media, including the Internet, satellite broadcasting, audio / video tapes, interactive television and CD-ROM. In addition, the educational institution most often uses the synchronous and asynchronous types of training for the existing distance learning program. There is a claim that online learning provides an opportunity to integrate a variety of curricula using modern technology. This contributes to effective collaborative learning, where students are separated from each other and use online learning platforms. Therefore, the use of e-education is appropriate, especially in working with a large number of students, as in a case-based distance learning program [7-11].

The following teaching aids are used in modern distance education: e-mail, television, radio, informational social networks.

The main means of distance learning are distinguished:

1. Online lecture - is the main form of obtaining educational material, which is carried out in real time using a specialized program such as Skype. This type of training session is held in the form of a conference, involving a dialogue between the teacher and the remote interlocutor through chat. The teacher can not only answer students questions, but also demonstrate video and photo materials.

2. Online seminars. Students receive training materials in advance, complete them, and the teacher holds a seminar in a question-and-answer format.

3. Individual online consultation - an individual form of communication between the teacher and the student in a "question-answer" format.

The student can go offline to the system at the links indicated by the teacher, where he can independently familiarize himself with and use the training material to prepare for the lesson.

When forming educational material, the teacher must take into account not only the specifics of the discipline, but also the individual characteristics of each student. This training resource package should contain various types of training materials with different levels of complexity (tests, cases, tasks, etc.). [8-12-13]

\section{SUMMARY}

Summarizing the above, we can offer basic techniques and working methods for distance individual learning.

First of all, the teacher must prepare the educational methodological complex of the discipline, which includes lectures (video files), assignments for practical exercises in the form of text files, test assignments (special programs), as well as additional materials in the form of electronic textbooks, audio files, etc.

A teacher's website should be created on the university's website, which is engaged in distance learning so that the student can get acquainted with the discipline (brief summary) and download the training material for the course (tasks, educational literature).

In addition to the implementation of individual distance learning, the university should monitor the process itself, for example, providing the 
necessary educational material to students, the time of lectures, seminars, consultations, test results, etc.

Also, for the organization of distance learning, the university must possess the necessary modern technical means, such as personal computers equipped with web cameras and microphones, the constant availability of the Internet, licensed software, as well as a complete set of educational material.

The training material that will be used in distance individual learning should contain the following:

- the schedule of the educational process, which includes the lesson schedule;

- audio and video materials of lectures, practical exercises;

- guidelines for the course;

- glossary;

- test tasks with automatic verification;

- References and links to digital libraries.

\section{CONCLUSIONS}

Modern distance individual learning meets the requirements, such as efficiency, flexibility, modularity and concurrency, which correspond to this type of training.

The fundamental difference between traditional and distance education is as follows: distance learning is based on the independent cognitive activity of the student. It is important that the student not only receives the necessary knowledge, but also learns to handle the information necessary for training. In the future, this skill will provide an opportunity to engage in continuing education. Distance individual learning is especially relevant for part-time students who combine study and work (career). Distance learning can be useful for full-time students. On the university's website, students can find the necessary textbooks, such as electronic textbooks, tests to verify the material studied, etc. Students can download textbooks for individual instruction $[9,10]$.

To summarize the above, we can conclude that distance individual education provides students with an independent learning environment. Students can study anywhere, anytime, using the necessary materials for this. In other words, the student is studying here and now. There is no doubt that the fact that distance individual education is an alternative type of education and its relevance will remain in the future.

\section{ACKNOWLEDGEMENTS}

The work is performed according to the Russian Government Program of Competitive Growth of Kazan Federal University.

\section{REFERENCE}

1. Blokhovtsova G.G., Malikova T.L., Simonenko A.A. New science: Strategies and development vectors. 2016. No. 118-3. P. 89-92.

2. Ilyin Aleksandr, Ibatova Aygul Orientation of the modern educational process on the concept of truth // National academy of managerial staff of culture and arts herald. - 2017 .-- Vol., Is. 2. - P.184-187.

3. Pashkina A. G. Distance learning as a means of individual work of a teacher with a student // Pedagogical education in Altai. 2014. No. 1. P. 201-203.

4. Spiros, R. K. (2003). Individual differences in motivation during distance training: The influence of goal orientation and self-efficacy on learning outcomes (Doctoral dissertation, ProQuest Information \& Learning).

5. Ibatova A.Z., Ilyin A.G. The study of the effectiveness of MOOCs in the modern educational space // Azimuth of scientific research: pedagogy and psychology. 2019.Vol. 8. No. 1 (26). P. 126-127.
6. Tarr, M. (1998). Distance learning-bringing out the best in training. IndustrialandCommercialTraining, 30 (3), 104-106.

7. Berge, Z. L., Muilenburg, L. Y., \& Haneghan, J. V. (2002). Barriers to distance education and training: Survey results. The Quarterly Review of Distance Education, 3 (4), 409-418.

8. Semenova I.N., Markelova E.S. Fundamentals of modeling individual educational trajectories of students with disabilities in distance learning // Pedagogical education in Russia. 2016. No. 7. P. 77-81.

9. Keegan, D. (2003). Distance training: Taking stock at a time of change. Routledge

10. Smirnova N. A. Learning management systems in distance education // Proceedings of the SIC Sociosphere conference. 2014. No. 25. P. 129-131

11. Suleri, J., \& Cavagnaro, E. Promoting pro-environmental printing behavior: The role of ICT barriers and sustainable values. International Journal of Education and Development using ICT, (2016). 12(2).

12. Kvet, M., \& Matiasko, K. Temporal Data Performance Optimization using Preprocessing Layer. Journal of Information Systems Engineering \& Management, (2018). 3(2), 13.

13. Abdul Rahman, S. Example Construction as a Devise to Reveal Awareness of Calculus Integration. International Electronic Journal of Mathematics Education, 14(1), (2019).233-241 https://doi.org/10.29333/iejme/3999

14. Abayeva, G. Modern teacher role for increasing the students' competence in pedagogical specialty. Opción, 34(85-2), (2018) 415-440. 